\title{
Alcohol Use among Swedish Patients with Stress-Induced Exhaustion Disorder, and Its Relation to Anxiety, Depression, and Health-Related Quality of Life
}

\author{
G. Grossi ${ }^{1,2}\left(D \cdot\right.$ K. Jeding $^{1} \cdot$ M. Söderström ${ }^{1,2} \cdot$ A. Perski $^{1} \cdot$ P. Alföldi ${ }^{1} \cdot$ W. Osika ${ }^{3}$
}

Accepted: 23 February 2021 / Published online: 22 March 2021

(C) The Author(s) 2021

\begin{abstract}
Harmful drinking may be a cause and an effect of psychological distress, and compromises the effects of treatment for psychiatric conditions. There is a paucity of studies investigating patterns of alcohol consumption among patients with stress-induced exhaustion disorder (SED). The aims of this investigation were (1) to assess the prevalence of self-rated hazardous drinking in a sample of 808 Swedish patients with SED (mean age $43 \pm 9$ years, $84 \%$ women), and (2) to investigate differences in sociodemographic variables, psychological symptoms, health-related quality of life, and sleep variables between patients with different drinking patterns The design was cross-sectional and data were collected with questionnaires at pre-treatment. Twelve percent of female and $13 \%$ of male patients reported Alcohol Use Disorder Identification Test (AUDIT) scores indicating hazardous drinking. Female patients with hazardous drinking reported higher levels of anxiety and depression and lower mental wellbeing, than other women. Female patients reporting no drinking reported poorer physical function and more pain, than other women. No differences were seen between male patients with different drinking patterns. Although patients with SED report a lower frequency of harmful drinking than other psychiatric samples, alcohol consumption needs to be addressed in the assessment and treatment of this condition.
\end{abstract}

Keywords Stress-induced exhaustion · Alcohol · AUDIT

\section{G. Grossi}

grossi@stressmottagningen.com

1 Stressmottagningen i Stockholm, The Stress Clinic Foundation, Stockholm, Sweden

2 Department of Clinical Neuroscience, Karolinska Institute, 17177 Stockholm, Sweden

3 Department of Neurobiology, Care Sciences and Society, Center for Social Sustainability, Karolinska Institute, 17177 Stockholm, Sweden 
In Sweden, stress-related psychiatric diagnoses are the leading causes of sick leave among both men and women (Swedish Social Insurance Agency 2016, 2017, 2018). The Swedish version of the International Classification of Diseases (ICD-10-SE; Swedish Board of Health and Welfare 2010) includes stress-related exhaustion disorder (SED) in order to capture the symptomatology of "clinical burnout", i.e. the sequelae of chronic stress without recovery. An individual fulfils the criteria for SED if (A) he or she has experienced psychological and physical exhaustion for at least 2 weeks (these symptoms must have developed as a consequence of clearly identified stressors, present for at least 6 months); (B) a significant lack of psychological energy or endurance dominates the clinical picture; and $(\mathrm{C})$ at least four of the following symptoms have been present virtually every day for the past 2 weeks: (1) problems with memory or concentration; (2) impaired ability to handle demands or to perform under time pressure; (3) emotional lability or irritability; (4) sleep disturbances; (5) significant physical fatigue and lack of endurance; (6) bodily symptoms such as muscular pain, chest pain, palpitations, gastrointestinal symptoms, dizziness, or hypersensitivity to sound. Besides causing significant distress and functional impairment, these symptoms must not be attributable to any other cause than stress at work or in the private sphere (Swedish Board of Health and Welfare 2010). SED is most prevalent among women, particularly those employed within the healthcare and educational systems, and among civil servants (Swedish Social Insurance Agency 2016, 2017; Swedish National Audit Office 2019). An estimated 9\% of Swedish primary care patients are diagnosed with SED (Glise 2014).

Severe SED that is not sufficiently ameliorated in primary healthcare or in the organizational healthcare motivates rehabilitation at specialized clinics offering multi-modal treatments. Many tertiary interventions have been evaluated (e.g. Stenlund et al. 2009, 2012; Perski et al. 2017), but to date, there is no well-established treatment for this condition. Data indicate that symptoms tend to improve irrespective of treatment (Wallensten et al. 2019), and that interventions specifically geared at work resumption are necessary in order to decrease sick leave and facilitate return to work (e.g. Van der Klink et al. 2003; Perski et al. 2017). It is therefore of great importance to consider all possible factors that may have an impact on the recovery from SED. One such factor could be patients' alcohol consumption.

The term hazardous drinking refers to a pattern of excessive use of alcohol which has not yet resulted in damage to one's physical or mental health but carries a high risk of such consequences. Individuals who ascribe alcohol relaxing and/or energizing properties may drink in a hazardous manner in order to cope with stress and negative emotions (Dawson et al. 2005; Frone 2016). Harmful drinking is a pattern of consumption that damages one's physical and/or mental health, and may have legal and/or social consequences. Although drinking may induce pleasurable short-term effects, it may also contribute to distressing symptoms of arousal, which are induced by increased excitatory and decreased inhibitory neurotransmitter activity during withdrawal (Mukherjee et al. 2008). In the long run, frequent alcohol-induced oscillations between inhibitory and excitatory influences may exert anxiogenic effects and thus lead to or worsen pre-existing psychiatric conditions (e.g. Castaneda et al. 1998; Boden and Fergusson 2011; Breese et al. 2011). Thus, stress and stress-related psychological ill-health may be both causes and effects of excessive alcohol consumption.

Furthermore, some individuals are at risk of developing dependence, a diagnosis that is made if three or more of the following have been experienced in the previous 12 months: (1) A strong desire or sense of compulsion to take alcohol; (2) difficulties in controlling alcohol 
taking behaviour; (3) physiological withdrawal state when alcohol ceased or reduced; (4) evidence of tolerance: increased doses required; (5) progressive neglect in alternative pleasures or interests because of alcohol use; (6) persisting with alcohol use in spite of clear evidence of harmful consequences (physical or mental) (Swedish Board of Health and Welfare 2010). Selfrated stress has been positively associated with increased drinking in predisposed individuals (e.g. Dawson et al. 2005; Heikkilä et al. 2012; Frone 2016), and there is great comorbidity between psychiatric disorders and hazardous drinking (e.g. Nehlin et al. 2012; Eberhardt et al. 2015) as well as alcohol dependence (Boden and Fergusson 2011; Smith and Randall 2012; Debell et al. 2014; Hasin and Grant 2015; Fein 2015). Harmful drinking also worsens the prognosis for and impedes optimal recovery from mental disorders (Castaneda et al. 1998; Haynes et al. 2008). It is therefore reasonable to assume that hazardous alcohol consumption may be a barrier to optimal rehabilitation for SED.

While the patterns of alcohol consumption among patients with SED are to date unexplored, it is of great importance to investigate this topic as problematic drinking and exhaustion may influence one another and compromise the effects of treatment. Therefore, the purpose of the present cross-sectional study was to assess the prevalence of self-rated hazardous drinking in a sample of Swedish patients with SED, who had been admitted for multi-modal rehabilitation for their condition. Another aim was to investigate differences in sociodemographic variables, psychological symptoms, health-related quality of life, and sleep variables between patients with different patterns of alcohol consumption. We hypothesized that patients reporting hazardous drinking would report higher levels of anxiety, depression, exhaustion, and sleep problems, and a lower health-related quality of life compared to non-drinkers and moderate drinkers. Data were analysed separately for men and women, as stress-related psychiatric diagnoses are more common among women (Swedish Social Insurance Agency 2016, 2017; Swedish National Audit Office 2019), but problematic drinking is more frequent among men (Swedish Health Agency 2019).

\section{Material and Methods}

\section{Participants}

A total of 1315 consecutive patients, referred to a specialized stress clinic from general practitioners and company healthcare services within the greater Stockholm area, were evaluated for participation in stress rehabilitation treatment between 2015 and 2019. All patients underwent clinical assessments in order to verify the diagnosis of SED, and to test their motivation to actively participate in a rehabilitation programme comprising psychotherapy, physiotherapy, and occupational therapy, mostly in a group format. The assessments were performed in accordance with the Swedish version of the ICD-10 (Socialstyrelsen 2010), with a physician, a psychologist, and either an occupational therapist or a physiotherapist. Of the 1315 potential study participants, 387 were excluded from the analyses because they were deemed to fulfil the criteria for other psychiatric and/or somatic morbidity than SED as their primary diagnosis, and 120 were excluded due to missing data. The mean age of the study sample was $43 \pm 9$ years, and the majority (84\%) were women. The 387 excluded patients with available data were more often males (excluded $24 \%$ versus included $16 \% ; \chi^{2}(1)=10.66$, $p<.001$ ), and had lower mean scores on the Shirom-Melamed Burnout Questionnaire 
$($ SMBQ; see below: excluded $=5.37 \pm 1.04$ versus included $=5.50 \pm .83 ; F(1,1107)=4.41$, $p<.05$ ), and the Mental Health subscale of the Short Form Health Survey (SF-36; see below: excluded $=40.95 \pm 19.14$ versus included $=44.33 \pm 17.89 ; F(1,1107)=7.73, p<.01)$. The 387 patients who were excluded from the study also had higher scores than those who were included on the "role limitations due to physical functioning" subscale of the SF-36 (excluded $=21.52 \pm 35.13$ versus included $=16.52 \pm 30.92$; Mann-Whitney $U=116,408.50, p<.05$ ). There was an overall difference in categorical AUDIT scores between excluded and included male patient groups $\left(\chi^{2}(2)=8.97, p<05\right)$, which was due to a higher frequency of moderate drinking among those included (included $79 \%$ versus excluded $62 \% ; \chi^{2}(1)=19.11, p<.001$ ). Among excluded male patients, there was a higher percentage of non-drinkers (excluded $18 \%$ versus included $8 \%$ ) and hazardous drinkers (excluded $18 \%$ versus included $13 \%$ ), but these differences were not significant.

\section{Measures}

In conjunction with the clinical assessments, participants were asked to fill out a questionnaire on sociodemographic variables and degree of sick leave at the time of data collection $(0 \%$, $25 \%, 50 \%, 75 \%$, and $100 \%$, respectively), as well as a number of scales assessing various facets of lifestyle habits, mental health, sleep, and health-related quality of life.

Alcohol consumption was assessed using the Alcohol Use Disorder Identification Test (AUDIT; Babor et al. 2001; Bergman et al. 1994; Berman et al. 2017), which is geared at identifying individuals with possible hazardous drinking behaviour and/or who are at risk of alcohol dependence. The scale consists of ten items and the possible responses to each question are scored $0,1,2,3$, or 4 , with the exception of questions 9 and 10, which have possible responses of 0,2 , and 4. AUDIT covers the three domains of consumption (three items about frequency and quantity of drinking), dependence (three items about cravings and loss of control over drinking), and harmful drinking (four items about problems caused by excessive drinking). A cut-off score of 6 and above on the total AUDIT index indicates hazardous drinking among women, while a cut-off score of 8 and above indicates hazardous drinking among men. Scores equal to or above 14 and 16 indicate harmful drinking and moderate risk of dependence among women and men, respectively, while scores equal to or above 18 and 20 indicate severe problems and a high risk for dependence among women and men, respectively.

The AUDIT is a tool for identifying persons with harmful alcohol consumption, but is not a diagnostic instrument in itself. In this study, we used the Swedish version of the AUDIT, which was translated to Swedish by Bergman and co-workers (1994), and has been shown to have a good validity and reliability (Bergman et al. 1998; Bergman and Källmén 2002; Berman et al. 2017).

The Shirom-Melamed Burnout Questionnaire (SMBQ; Melamed et al. 1992; Shirom et al. 1997; Melamed et al. 1999) contains 22 items (graded 1-7) that measure burnout, conceptualized as the chronic depletion of an individual's energetic resources as a consequence of longstanding stress. The Swedish version of the SMBQ has been found to be strongly correlated with the emotional exhaustion subscale of the Maslach Burnout Inventory, and with the Pines Burnout Measure (Grossi et al. 2003). Patients with SED score regularly high on the SMBQ (Glise et al. 2012, 2014; Stenlund et al. 2007), which is a standard assessment tool in the specialized care units for SED in the Stockholm region. 
A global SMBQ index was calculated for each participant. In the present study, the internal reliability of the SMBQ was satisfactory (Cronbach's alpha .81).

Symptoms of anxiety and depression were assessed using the Hospital Anxiety and Depression Scale (HADS; Zigmond and Snaith 1983). This instrument consists of 14 items to be answered on a scale graded from 0 to 3, seven of them measuring anxiety (HADS-A) and seven depression (HADS-D). High scores correspond to high anxiety and depression. A cutoff score of 10 was used in the present study. The Swedish version of the HAD has been shown to have satisfactory factor structure, as well as acceptable concurrent validity (Lisspers et al. 1997). In this study, Cronbach's alpha coefficients were .82 for HADS-A and .82 for HADS-D, indicating good internal reliability of the scales.

The Short Form Health Survey version 1 (SF-36; Ware and Sherbourne 1992; Ware et al. 1993; Sullivan et al. 2002) was used to assess the patients' perceptions of their health status and its impact on their quality of life. The scale consists of 36 items summarized in eight subscales - physical functioning (10 items), role limitations due to physical problems (4 items), bodily pain ( 2 items), general health ( 5 items), vitality (4 items), mental health (5 items), social functioning ( 2 items), and role limitations due to emotional problems (3 items)and two summary scores (the Physical Component Summary (PCS) score and the Mental Component Summary (MCS) score. An additional item reports health transition over the past year. The items are to be answered on a scale from 1 to 5 . Raw scores were transformed into standard scores ranging from 0 to 100 . High scores indicating a better health-related quality of life, and a mean score of 50, are a normative value for all scales (Ware et al. 1993). The psychometric properties of the Swedish version of the SF-36 have been tested in the Swedish general population (Sullivan et al. 1995), and found to be satisfactory.

Cronbach's alpha for the SF-36 subscales was .87 for physical functioning, .87 for role limitations due to physical problems, .86 for bodily pain, .82 for mental health, .92 for general health, .79 for vitality, .80 for social functioning, and .83 for and role limitations due to emotional problems.

The Karolinska Sleep Questionnaire (KSQ; Ingre et al. 2000; Nordin et al. 2013) aimed at assessing various aspects of sleep and sleepiness. The KSQ also contains four questions reflecting poor quality of sleep ("difficulties falling asleep", "repeated awakenings with difficulties falling asleep again", "premature awakenings", "disturbed/restless sleep"), three questions measuring the sensation of not feeling refreshed on awakening ("difficulties waking up", "not well rested on awakening", "being exhausted on awakening"), six measuring the presence of sleepiness and/or fatigue during the day ("felt sleepy during work", "felt sleepy during leisure time", "involuntary dozing off at work", "involuntary dozing off during leisure time", "need to fight sleep to stay awake", "tired in the head during daytime"), and three measuring symptoms of apnoea ("heavy snoring", "gasping for breath during sleep", "cessation of breathing during sleep"). The response categories include five alternatives ranging from 1 (never/very good) to 5 (almost every day/very bad). Items were summed up in the four indices of sleep quality, awakening, sleepiness/fatigue, and apnoea. High scores for these indices indicate poor quality of sleep, fatigue on awakening, protracted sleepiness/fatigue during the day, and heavy snoring and apnoea during sleep. The KSQ has been shown to have satisfactory validity and reliability (Nordin et al. 2013; Westerlund et al. 2014). In the present study, the internal consistency was good for three of the subscales and discussable for one index: Cronbach's alpha was .77 for sleep quality, .69 for awakening, .81 for sleepiness/ fatigue, and .77 for apnoea. 
The Epworth Sleepiness Scale (ESS; Johns 1991) was used to measure daytime sleepiness. The ESS consists of eight items graded from 0 to 3 asking the respondent to rate his or her probability of falling asleep in a number of common daily situations. A sum score above 10 indicates severe daytime sleepiness and an increased risk of a sleep disorder, such as apnoea, narcolepsy, or idiopathic hypersomnia (Johns 1991, 2000). The ESS has good psychometric properties (e.g. Johns 1992) and is highly correlated with other, well-established scales for the measurement of sleep disturbances (Knutson et al. 2006). In our study, Cronbach's alpha was .83 , indicating a good internal consistency of the scale.

\section{Statistical Analyses}

Data were analysed using the IBM SPSS statistical package, version 26. Differences between groups were analysed with univariate analyses of variance (ANOVAs), $\chi^{2}$ tests, and KruskalWallis and Mann-Whitney tests. An alpha level of 0.05 was considered to be of statistical significance for all planned analyses, but not for the post hoc tests. In view of the large number of post hoc comparisons, a Bonferroni correction was applied to these analyses with Tukey's tests, which were not considered significant unless their $P$-values were less than 0.0167 . Data were lost for several measures, as indicated by $n$ and the degrees of freedom.

\section{Results}

\section{Patterns of Alcohol Use}

Ninety-five patients (12\%) reported a score of 0 on the AUDIT (Table 1). The total number of patients with AUDIT scores above the cut-off of 6 for women and 8 for men was 100 (12\%; Table 1). Seventeen (2\%) were males and 83 (10\%) females, which corresponds to $13 \%$ of all males and $12 \%$ of all females. As seen in Table 1, one male patient scored above 16 and seven female patients scored above 14 on the AUDIT, which indicates harmful drinking. One female patient scored above 18, which indicates a strong risk of dependence. Based on their answers on the AUDIT, female patients were allocated to a "non-drinking" group (scoring $0 ; n=85$ ), a "moderate drinking" group (scoring $1-5 ; n=513$ ), and a "hazardous drinking" group (scoring $\geq 6 ; n=83$ ). Due to their small numbers, female patients with scores indicating harmful drinking and/or dependence were included in the last group.

Similarly, male patients were allocated to a "non-drinking" group (scoring $0 ; n=10$ ), a "moderate drinking" group (scoring $1-7 ; n=100$ ), and a "hazardous drinking" group (scoring $\geq 8 ; n=17$ ). The male patient scoring above 16 on the AUDIT was included in the last group.

Table 1 Patterns of alcohol consumption among patients with exhaustion disorder

\begin{tabular}{llll}
\hline AUDIT scores & All $(n=808)$ & Females $(n=681)$ & Males $(n=127)$ \\
\hline 0 & $95(12 \%)$ & $85(13 \%)$ & $10(8 \%)$ \\
Moderate & $613(76 \%)$ & $513(75 \%)$ & $100(79 \%)$ \\
Hazardous & $91(11 \%)$ & $75(11 \%)$ & $16(12 \%)$ \\
Harmful & $8(.9 \%)$ & $7(.9 \%)$ & $1(1 \%)$ \\
Dependence & $1(.1 \%)$ & $1(.1 \%)$ & 0 \\
\hline
\end{tabular}

AUDIT, Alcohol Use Disorder Identification Test 


\section{Sociodemographic Differences}

The patients' sociodemographic data are displayed in Table 2. A series of $\chi^{2}$ analyses among female patients revealed overall differences in the frequency of being married $\left(\chi^{2}(2)=6.61\right)$, employed $\left(\chi^{2}(2)=6.32, p<.05\right)$, and self-employed $\left(\chi^{2}(2)=11.01, p<.001\right)$, and in the degree of sick leave $\left(\chi^{2}(2)=10.70, p<.001\right)$. Follow-up analyses showed that female patients in the "hazardous drinking" group were less frequently married than their counterparts in the "moderate drinking" group $\left(\chi^{2}(1)=6.59, p<.05\right)$, less frequently employed than participants in the "non-drinking" group $\left(\chi^{2}(1)=5.13, p<.05\right)$, and the "moderate drinking" group $\left(\chi^{2}\right.$ $(1)=4.65, p<.05)$, and more often self-employed than those in the "non-drinking" group $\left(\chi^{2}\right.$ $(1)=9.25, p<01)$ and the "moderate drinking" group $\left(\chi^{2}(1)=6.19, p<05\right)$. The frequency of participants on sick leave was higher in the female "non-drinking" group compared to the "hazardous drinking" group $\left(\chi^{2}(1)=12.21, p<.001\right)$ and the "moderate drinking" group $\left(\chi^{2}\right.$ $(1)=8.47, p<.01)$. Also, participants in the "non-drinking" group were on $100 \%$ sick leave more often than their counterparts in the "moderate drinking" group $\left(\chi^{2}(1)=5.44, p<.05\right)$.

Among male patients, there was an overall difference in unemployment rates $\left(\chi^{2}(2)=\right.$ $11.24, p<.01)$, which was due to a higher level of unemployment in the "non-drinking" group compared to the "moderate drinking" group $\left(\chi^{2}(1)=12.37, p<.01\right)$.

Differences in self-rated exhaustion, anxiety, depression, health-related quality of life, and sleep variables are illustrated in Table 3. A univariate ANOVA performed among female patients revealed a significant overall difference in scores for the $\operatorname{SMBQ}(F(2,668)=3.23$, $p<.05)$, which was ruled out after Bonferroni correction $(p>.0167)$. There was also a significant overall difference in scores for the HADS-A $(F(2,680)=8.22, p<.001)$, which was due to higher ratings in the "hazardous drinking" group compared to the "moderate drinking" group $(p<.0167) \cdot \chi^{2}$ tests confirmed that the "hazardous drinking" group had a significantly higher proportion of female participants scoring above the cut-off for the HADSA than the "moderate drinking" group $\left(\chi^{2}(1)=4.81, p<.05\right)$, and also more participants scoring above the cut-off for HADS-D than both the "moderate drinking" group $\left(\chi^{2}(1)=7.58\right.$, $p<.01)$ and the "non-drinking" group $\left(\chi^{2}(1)=5.16, p<.05\right)$.

Further univariate ANOVAs among female patients yielded significant overall differences for the SF-36 subscales physical functioning $(F(2,667)=9.34, p<.0001)$, bodily pain $(F(2$, $667)=3.46, p<.05)$, general health $(F(2,667)=6.49, p<.01)$, social functioning $(F(2,668)=$ $5.02, p<.01)$, and mental health $(F(2,668)=5.68, p<.01)$, as well as for the SF-36 physical component summary $(F(2,666)=13.99, p<.001)$ and mental component summary $(F(2$, $666)=6.57, p<.01)$. Furthermore, there was an overall difference in scores for the KSQ subscale awakening $(F(2,677)=3.14, p<.05)$.

Post hoc tests with Bonferroni and Tukey's tests revealed that the female "hazardous drinking" group had lower scores on the SF-36 subscale mental health than the female "moderate drinking" group $(p<.0167)$, and lower scores for the mental component summary than both other female groups (all $p<.0167$ ). The female "non-drinking" group, on the other hand, had lower mean scores on the SF-36 subscale physical functioning, general health, and the physical component summary than both other female groups (all $p<.017$ ).

The overall differences in mean scores for the SF-36 subscales bodily pain, social functioning, and KSQ-awakening were ruled out after Bonferroni correction (all $p>.0167$ ). Differences in scores for the SF-36 subscales physical role function and emotional role function were analysed using Kruskal-Wallis and Mann-Whitney tests, due to excessive skewness in the scores' distributions. The results showed an overall difference in median 


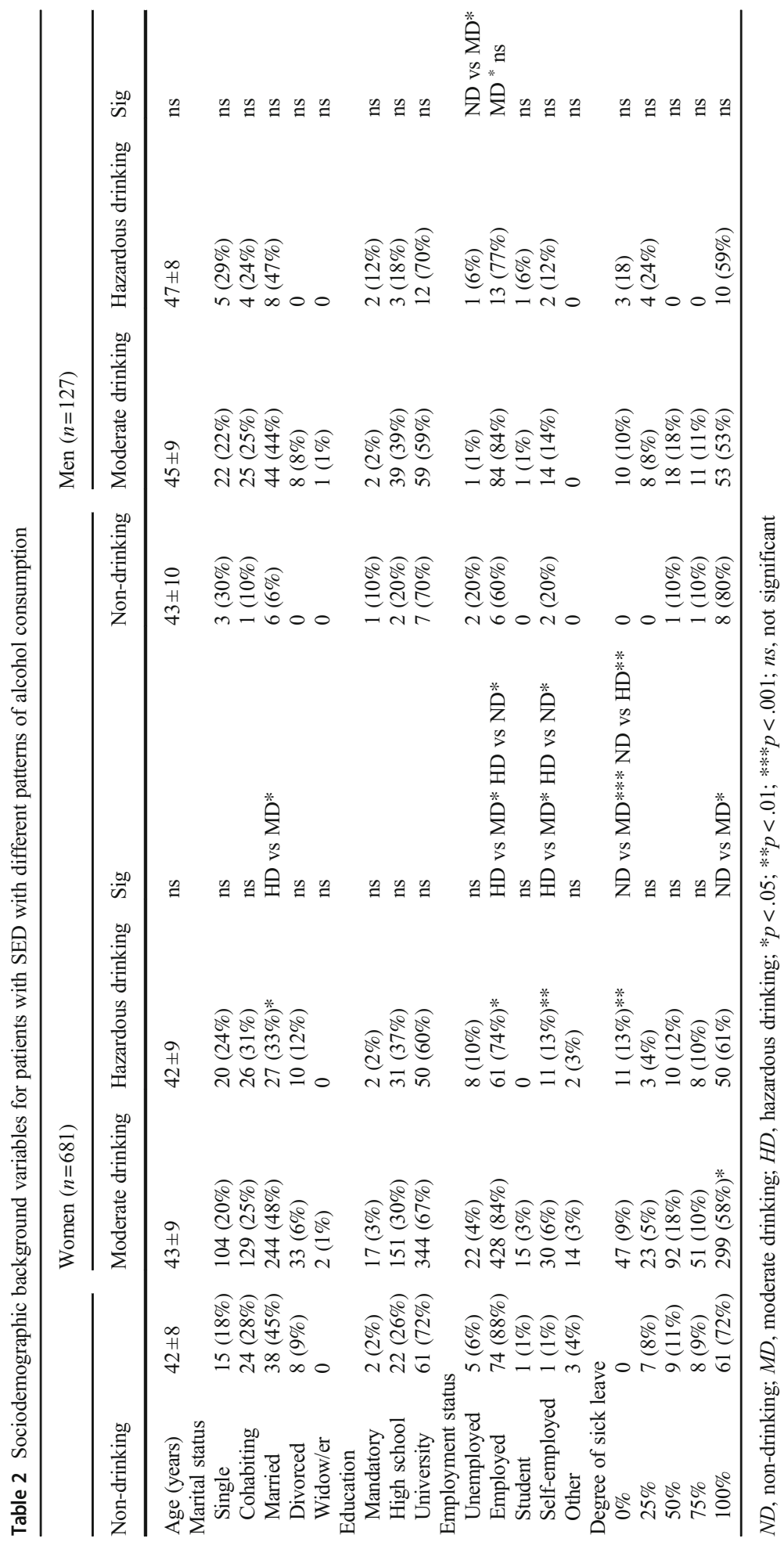




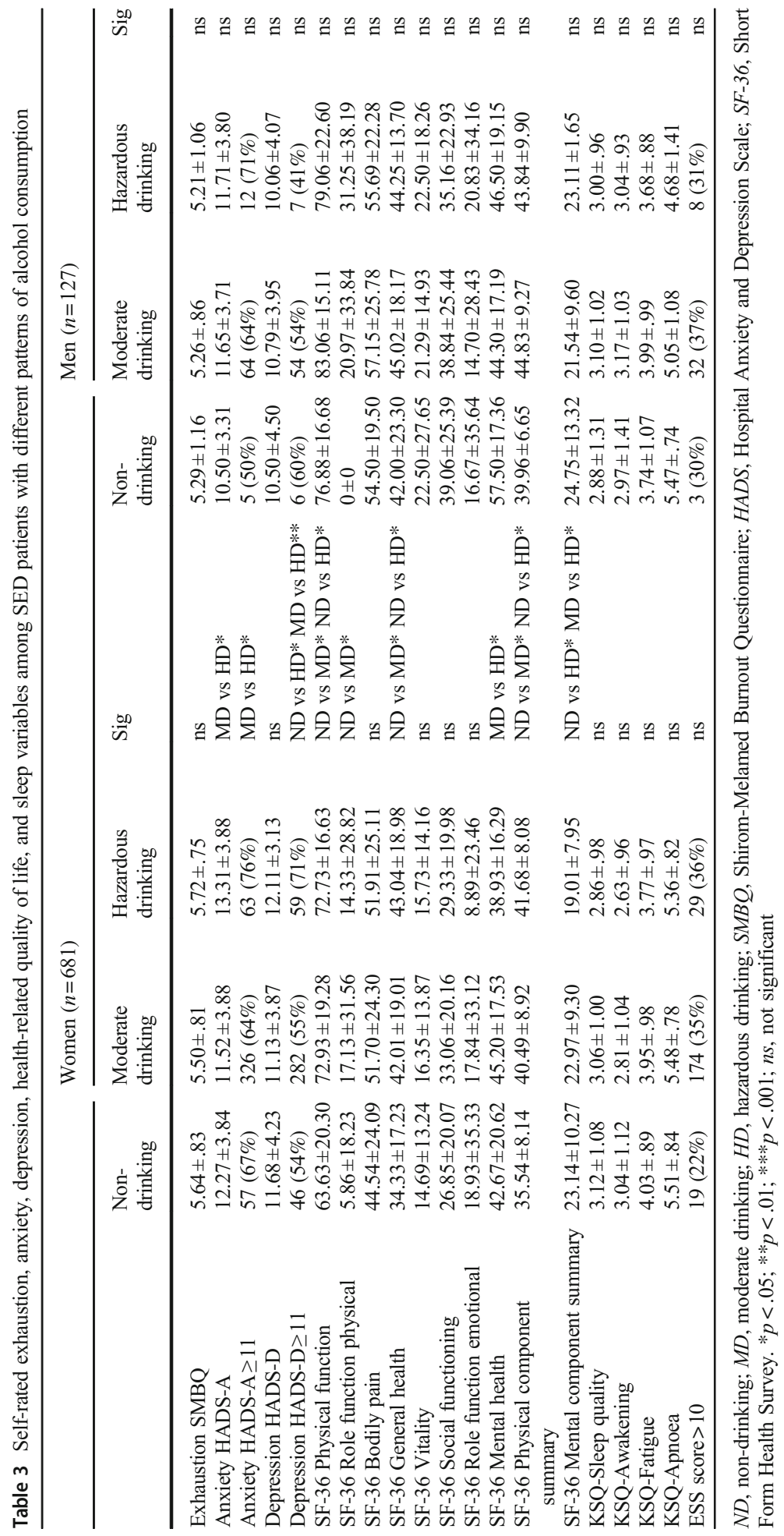


scores for "physical role function" $(H(2)=10.23, p<.01)$, which was due to lower values in the female "non-drinking" group compared to the "moderate drinking" group (Mann-Whitney $U(1)=17,748.50, p<.01)$. The results remained virtually unchanged when performing the analyses with exclusion of the eight female patients scoring above 14 on the AUDIT. No significant differences between female groups were seen in emotional role function.

No significant group differences were observed among male patients.

\section{Discussion}

In the present study performed among patients with SED, the rates of self-rated hazardous drinking were $12 \%$ for females and $13 \%$ for males. According to a survey performed by the Swedish Health Agency (2019), the corresponding rates in the general population are $20 \%$ among men and $13 \%$ among women. At least among male patients, the prevalence of hazardous drinking found in the present sample was well below that seen in the general population. Excessive drinking is regarded as a differential diagnostic factor to be considered when diagnosing SED, since alcohol misuse per se can lead to the development of fatigue, cognitive difficulties, sleep disturbances, and mood impairments which are also common in SED. One possible explanation for the relatively low rates of hazardous drinking seen in the present study could be that many SED patients with unhealthy alcohol consumption may have been detected during clinical assessments by their general practitioners and, thus, have not been referred to treatment at the specialist level. Some may also have been excluded from participating in the rehabilitation programme after having been assessed by the staff at the stress clinic and identified as exhibiting hazardous drinking and therefore referred to, for instance, an alcohol treatment clinic. The observed differences in drinking patterns between patients who were and were not admitted to rehabilitation support this notion. Unfortunately, no physiological marker of alcohol consumption was employed. The extent to which alcohol consumption may have been underreported is therefore unknown.

To our knowledge, there are no previous studies of alcohol consumption among SED patients, and therefore, no data with which we could compare our results. However, our findings stand in contrast to data showing high rates of hazardous drinking in other psychiatric disorders. In a Swedish study among non-psychotic psychiatric outpatients, Nehlin et al. (2012) found that $28 \%$ of women and $31 \%$ of men reported AUDIT scores indicating hazardous drinking. The corresponding rates seen in a similar study among general psychiatric outpatients by Eberhardt et al. (2015) were $22 \%$ among women and $30 \%$ among men. The number of SED patients with AUDIT scores indicating harmful drinking and possible dependence was also very low. The lifetime rates of comorbidity with alcohol dependence are up to $85 \%$ in anxiety disorders and mood disorders, which often overlap with SED (Fein et al. 2007: Fein 2015). In a study in the general Finnish population, Ahola et al. (2006) found significant associations between alcohol dependence and burnout as measured using the Maslach Burnout Inventory, a construct that is conceptually related to SED.

In line with the hypothesis, female patients scoring above the cut-off for the AUDIT reported higher levels of anxiety and depression, and poorer mental health, assessed using the SF-36, than the other groups. They also had a different sociodemographic profile, being more seldom married, more frequently self-employed, and to a lesser extent on sick leave. Hypothetically, individuals who live alone and/or are self-employed experience greater financial uncertainty than their counterparts and may feel pressured to work despite illness. It is possible for a self-employed person to avoid being on 
formal sick leave in a way that is not possible for an employed person, so that formal sick leave status in the group of self-employed reflects actual work disability to a lesser extent. Taken together, these factors may exacerbate stress and impede optimal recovery from SED. Furthermore, predisposed individuals may recur to drinking in an attempt to cope with anxiety, fatigue, and other unpleasant emotions (e.g. Frone 2016). In the long run, drinking may also be a hindrance to recovery from SED, through deteriorations in one's mental and physical health, and a reduced ability to address problems in one's life situation.

Approximately $12 \%$ of the study participants reported AUDIT scores of 0 , which is slightly below the $14 \%$ rate of non-drinkers in the study by Eberhard et al. (2015). Contrary to expectations, female patients in the "non-drinking" group reported poorer physical functioning than the other groups, expressed by lower scores on the SF-36 indices physical functioning and general health, and the physical component summary. A possible explanation for this finding is that a subgroup of SED patients with comorbid somatic ailments may be less inclined to consume alcohol due to their multiple health conditions. Previous research indicates that samples reporting total abstinence may, in fact, be heterogeneous and include healthy individuals as well as individuals who refrain from drinking due to poorer health (e.g., Saito et al. 2005; Heikkilä et al. 2012). Saito and co-authors (2005), for instance, found that light or moderate drinkers were more likely to rate their health as good compared to non-drinkers in a study comprising male workers. Similar findings were reported by Heikkilä et al. (2012) in a meta-analysis of studies on the associations between alcohol consumption and job strain. Interestingly, clinical observations indicate that many patients with SED report cutting down their use of alcohol, as well as of nicotine, coffee/caffeine, and sweets, due to a self-rated intolerance of these substances' side effects.

Somewhat surprisingly, we saw very small group differences in sleep variables. Poor sleep is one of the diagnostic features of SED (Swedish Board of Health and Welfare 2010), and is negatively affected by alcohol consumption (Ebrahim et al. 2013) and present in anxiety and depression (Cox and Olatunji 2016). The findings here suggest that the SED patients included in the present study tended to have comparable sleep patterns irrespective of drinking habits.

Besides a difference in unemployment levels, the results showed no group differences among male patients. This finding may be due to the relatively small size of the male sample and deserves further investigation in future studies.

The study has some limitations that need to be considered. Its cross-sectional design precludes causal interpretations of the results and does not allow for assessments of the prognostic importance of alcohol consumption in rehabilitation for SED. Data were collected by means of questionnaires and the results were not corroborated by objective measures, such as blood tests. Data collection was performed at a single clinic within the greater Stockholm area, which may make it difficult to generalize the results to the larger population of patients with SED. However, the high frequency of female patients and the age span observed in the study sample are in line with observations made by others (e.g. Social Insurance Agency 2018).

Despite these limitations, the results offer new information about the associations between alcohol consumption and the clinical picture of patients with SED. In clinical settings, special attention should be paid to the identification of patients with hazardous drinking habits, since they tend to report higher levels of emotional distress. According to the results, single, selfemployed women may be at risk for maladaptive coping by means of drinking, as a response to stress. Patients who report no drinking at all should also be assessed more carefully, since this group could be heterogeneous and contain individuals with poorer somatic health. The importance of alcohol consumption for the long-term prognosis of patients with SED remains to be elucidated in future studies. 
Funding Open access funding provided by Karolinska Institute.

\section{Declarations}

Conflict of Interest The authors declare no conflict of interest.

Ethical Approval A sample of 808 consecutive patients who were admitted for rehabilitation at the stress clinic were thus included in the study, which was approved by the Ethics Committee at the Karolinska Institute (Dnr 2019-04559).

Open Access This article is licensed under a Creative Commons Attribution 4.0 International License, which permits use, sharing, adaptation, distribution and reproduction in any medium or format, as long as you give appropriate credit to the original author(s) and the source, provide a link to the Creative Commons licence, and indicate if changes were made. The images or other third party material in this article are included in the article's Creative Commons licence, unless indicated otherwise in a credit line to the material. If material is not included in the article's Creative Commons licence and your intended use is not permitted by statutory regulation or exceeds the permitted use, you will need to obtain permission directly from the copyright holder. To view a copy of this licence, visit http://creativecommons.org/licenses/by/4.0/.

\section{References}

Ahola, K., Honkonen, T., Pirkola, S., Isometsä, E., Kalimo, R., Nykyri, E., Aromaa, A., \& Lönnqvist, J. (2006). Alcohol dependence in relation to burnout among the Finnish working population. Addiction, 101, 14381443.

Babor, T., Higgins-Biddle, J C., Aaunders, J. B., Monteiro, M. G. (2001). Audit. The alcohol disorders identification test. Guidelines for use in primary care. Second ed. WHO.

Bergman, H., \& Källmén, H. (2002). Alcohol use among swedes and a psychometric evaluation of the alcohol use disorders identification test. Alcohol \& Alcoholism, 37(3), 245-251.

Bergman, H., Källmén, H., Rydberg, U., Sandahl, C. (1994). Audit. The alcohol use disorder identification test. Manual, svensk översättning, Karolinska institutet, tidigare översatt 1994.

Bergman, H., Källmén, H., Rydberg, U., \& Sandahl, C. (1998). Tio frågor om alkohol identifierar beroendeproblem. Psykometrisk prövning på psykiatrisk akutmottagning. Läkartidningen, 95(43), 43714335 .

Berman, A.H., Wennberg, P., Källmen, H. (2017). AUDIT \& DUDIT. Identifiera problem med alkohol och droger. (AUDIT \& DUDIT: Identifying problems with alcohol and drugs). Gothia Fortbildning AB.

Boden, J. M., \& Fergusson, D. M. (2011). Alcohol and depression. Addiction, 106, 906-914.

Breese, G. R., Sinha, R., \& Heilig, M. (2011). Chronic alcohol neuroadaptation and stress contribute to susceptibility for alcohol craving and relapse. Pharmacology and Therapeutics, 129, 149-171.

Castaneda, R., Sussman, N., Levy, R., O'Malley, M., \& Westreich, L. (1998). A review of the effects of moderate alcohol intake on psychiatric and sleep disorders. Recent Developments in Alcoholism, 14, 197-226.

Cox, R. C., \& Olatunji, B. O. (2016). A systematic review of sleep disturbance in anxiety and related disorders. Journal of Anxiety Disorders, 37, 104-129.

Dawson, D., Grant, B. F., \& Ruan, W. J. (2005). The association between stress and drinking: modifying effects of gender and vulnerability. Alcohol and Alcoholism, 40(5), 453-460.

Debell, F., Fear, N. T., Head, M., Batt-Rawden, S., Greenberg, N., Wessely, S., \& Goodwin, L. (2014). A systematic review of the comorbidity between PTSD and alcohol misuse. Social Psychiatry and Psychiatric Epidemiology, 49, 1401-1425.

Eberhardt, E., Nordström, G., \& Öjehagen, A. (2015). Hazardous alcohol use in general psychiatric outpatients. Journal of Mental Health, 24(3), 162-167.

Ebrahim, I. O., Shapiro, C. M., Williams, A. J., \& Fenwick, P. B. (2013). Alcohol and sleep I: effects on normal sleep. Alcoholism: Clinical and Experimental Research, 37, 539-549.

Fein, G. (2015). Psychiatric comorbidity in alcohol dependence. Neuropsychological Reviews, 25, 456-475.

Fein, G., Di Sclafani, V., Finn, P., \& Scheiner, D. L. (2007). Sub-diagnostic psychiatric comorbidity in alcoholics. Drug and Alcohol Dependence, 87(2-3), 139-145. 
Frone, M. R. (2016). Work stress and alcohol use: developing and testing a biphasic self-medication model. Work and Stress, 30(4), 374-394.

Glise, K. (2014). Exhaustion disorder - identification, characterisation and course of illness. Doctoral dissertation, University of Gothemburg.

Glise, K., Ahlborg, J. G., \& Jonsdottir, I. H. (2012). Course of mental symptoms in patients with stress-related exhaustion: does sex or age make a difference? BMC Psychiatry, 12(18).

Glise, K., Ahlborg, J. G., \& Jonsdottir, I. H. (2014). Prevalence and course of somatic symptoms in patients with stress-related exhaustion: does sex or age matter. BMC Psychiatry, 14(1).

Grossi, G., Perski, A., Evengard, B., Blomkvist, V., \& Orth-Gomer, K. (2003). Physiological correlates of burnout among women. Journal of Psychosomatic Research, 55, 309-316. https://doi.org/10.1016/S00223999(02)00633-5.

Hasin, D. S., \& Grant, B. F. (2015). The national epidemiologic survey on alcohol and related conditions (NESARC) waves 1 and 2: review and summary of findings. Social Psychiatry and Psychiatric Epidemiology, 50, 1609-1640.

Haynes, J. C., Farrel, M., Singleton, N., \& Meltzer, H. (2008). Alcohol consumption as a risk factor for nonrecovery from common mental disorder: results from the longitudinal follow-up of the National Psychiatric Morbidity Survey. Psychological Medicine, 38, 451-455.

Heikkilä, K., Nyberg, S. T., Fransson, E. I., Alfredsson, L., De Bacquer, D., Bjorner, J. B., Bonenfant, S., Borritz, M., Burr, H., Clays, E., Casini, A., Dragano, N., Erbel, R., Geuskens, G. A., Goldberg, M., Hooftman, W. E., Houtman, I. L., Joensuu, M., Jöckel, K. H., Kittel, F., Knutsson, A., Koskenvuo, M., Koskinen, A., Kouvonen, A., Leineweber, C., Lunau, T., Madsen, I. E. H., Magnusson Hanson, L., Marmot, M. G., Nielsen, M. L., Nordin, M., Pentti, J., Salo, P., Rugulies, R., Steptoe, A., Siegrist, J., Suominen, S., Vahtera, J., Virtanen, M., Väänänen, A., Westerholm, P., Westerlund, H., Zins, M., Theorell, T., Hamer, M., Ferrie, J. E., Singh-Manoux, A., Batty, G. D., \& Kivimäki, M. (2012). Job strain and alcohol intake: a collaborative meta-analysis of individual participant data from 140000 men and women. PLoS One, 7(7), 1-7.

Ingre, M., Söderström, M., Kecklund, G., Åkerstedt, T., Kecklund, G. (2000). Lokförares arbetssituation med focus på arbetstider, sömn, stress och säkerhet. (Train drivers work situation: working hours, sleep, stress and safety). Institute for Psychosocial Medicine: Stress Research Report No 292. ISSN 0280-2783.

Johns, M. W. (1991). A new method for measuring daytime sleepiness: the Epworth sleepiness scale. Sleep, 14, $540-545$.

Johns, M. W. (1992). Reliability and factor analysis of the Epworth sleepiness scale. Sleep, 15, 376-381.

Johns, M. W. (2000). Sensitivity and specificity of the multiple sleep latency test (MSLT), the maintenance of wakefulness test and the Epworth sleepiness scale: failure of the MSLT as a gold standard. Journal of Sleep Research, 9, 5-11.

Knutson, K.L., Rathouz, P.J., Yan, L.L., Liu, K., Lauderdale, D.S. (2006). Stability of the Pittsburgh Sleep Quality Index and the Epworth Sleepiness Questionnaires over 1 year in early middle-aged adults: the CARDIA study. Sleep, 1503-1506.

Lisspers, J., Nygren, A., \& Söderman, E. (1997). Hospital Anxiety and Depression Scale (HAD): some psychometric data for a Swedish sample. Acta Psychiatrica Scandinavica, 96, 281-286.

Melamed, S., Kushnir, T., \& Shirom, A. (1992). Burnout and risk factors for cardiovascular diseases. Behavioral Medicine, 18(2), 53-60.

Melamed, S., Ugarten, U., Shirom, A., Kahana, L., Lerman, Y., \& Froom, P. (1999). Chronic burnout, somatic arousal and elevated cortisol levels. Journal of Psychosomatic Research, 6, 591-598.

Mukherjee, S., Kumar Das, S., Vaidyanathan, K., \& Vasudevan, D. M. (2008). Consequences of alcohol consumption on neurotransmitters - an overview. Current Neurovascular Research, 5, 266-272.

Nehlin, C., Fredriksson, A., \& Jansson, L. (2012). Brief alcohol screening in a clinical psychiatric population: special attention needed. Drug and Alcohol Review, 31, 538-543.

Nordin, M., Åkerstedt, T., \& Nordin, S. (2013). Psychometric evaluation and normative data for the Karolinska Sleep Questionnaire. Sleep and Biological Rythms, 11(4), 216-226.

Perski, O., Grossi, G., Perski, A., \& Niemi, M. (2017). A systematic review and meta-analysis of tertiary interventions in clinical burnout. Scandinavian Journal of Psychology, 58(6), 551-561.

Saito, I., Okamura, T., Fukuhara, S., Tanaka, T., Suzukamo, Y., Okayama, A., \& Ueshima, H. (2005). A crosssectional study of alcohol drinking and health-related quality of life among male workers in Japan. Journal of Occupational Health, 47, 496-503.

Shirom, A., Westman, M., Shamai, O., \& Carel, R. S. (1997). The effects of work overload and burnout on cholesterol and triglyceride levels: the moderating effects of emotional reactivity among male and female employees. Journal of Occupational Health Psychology, 2, 275-288.

Smith, J. P., \& Randall, C. L. (2012). Anxiety and alcohol use disorders. Alcohol Research, 34(4), $414-431$. 
Stenlund, T., Ahlgren, C., Lindahl, B., Burell, G., Knutsson, A., Stegmayr, B., \& Birgander, L. S. (2007). Patients with burnout in relation to gender and a general population. Scandinavian Journal of Public Health, 35, 516-523. https://doi.org/10.1080/14034940701271874.

Stenlund, T., Ahlgren, C., Lindahl, L., Burell, G., Steinholtz, K., Edlund, C., Nilsson, L., Knutsson, A., \& Slunga Birgander, L. (2009). Cognitive oriented behavioral rehabilitation in combination with Qigong for patients on long-term sick leave because of burnout: REST- a randomized clinical trial. Journal of Behavioral Medicine, 16, 294-303.

Stenlund, T., Nordin, M., \& Slunga Järvholm, L. (2012). Effects of rehabilitation programmes for patients on long-term sick leave for burnout: a 3-year follow-up of the REST study. Journal of Rehabilitation in Medicine, 44, 684-690.

Sullivan, M., Karlsson, J., \& Taft, C. (2002). SF-36 Hälsoenkät: Svensk Manual och Tolkningsguide, 2:a uppl. Göteborg: Sahlgrenska universitetssjukhuset.

Sullivan, M., Karlsson, J., \& Ware, J. E. (1995). The Swedish SF-36 Health Survey-I. Evaluation of data quality, scaling assumptions, reliability and construct validity across general populations in Sweden. Social Science and Medicine, 41, 1349-1358.

Swedish Board of Health and Welfare. (2010). Internationell statistisk klassifikation av sjukdomar och relaterade hälsoproblem - ICD-10-SE. (International statistical classification of diseases and related health problemsICD-10-SE). ISBN: 978-91-86585-63-1.

Swedish National Audit Office. (2019). Jämställd sjukfrånvaro (Gender-equal sickness absence): 2019:19. Stockholm.

Swedish Social Insurance Agency (2016). Sjukskrivning för reaktioner på svår stress ökar mest (Sick-leave due to reactions to severe stress increase the most). (Psykisk ohälsa, Korta analyser 2016:2.

Swedish Social Insurance Agency. (2017). Psykiatriska diagnoser. Lång väg tillbaka till arbete vid sjukskrivning (Psychiatric diagnoses. A long way back to work from sick-leave). Korta analyser 2017:1.

Swedish Social Insurance Agency (2018). Uppföljning av sjukfrånvarons utveckling (Follow-up of the development of sick-absenteeism). Report 002671-2018.

Van der Klink, J. J., Blonk, R. W., Schene, A. H., \& van Dijk, F. J. (2003). Reducing long term sickness absence by an activating intervention in adjustment disorders: a cluster randomized controlled design. Occupational and Environmental Medicine, 60, 429-437.

Wallensten, J., Åsberg, M., Wiklander, M., \& Nager, A. (2019). Role of rehabilitation in chronic stress-induced exhaustion disorder: a narrative review. Journal of Rehabilitation Medicine, 51, 331-342.

Ware Jr., J. E., \& Sherbourne, C. D. (1992). The MOS 36-item short-form health survey (SF-36). I. Conceptual framework and item selection. Medical Care, 30, 473-483.

Ware, J. E., Snow, K. K., Kosinski, M., \& Gandek, B. (1993). SF-36 health survey: manual and interpretation guide. Boston: The Health Institute, New England Medical Center.

Westerlund, A., Brandt, L., Harlid, R., Åkerstedt, T., \& Trolle Lagerros, Y. (2014). Using the Karolinska Sleep Questionnaire to identify obstructive sleep apnea syndrome in a sleep clinic population. The Clinical Respiratory Journal, 8, 444-454.

Zigmond, A. S., \& Snaith, R. P. (1983). The hospital anxiety and depression scale. Acta Psychiatrica Scandinavica, 67, 361-370.

Publisher's Note Springer Nature remains neutral with regard to jurisdictional claims in published maps and institutional affiliations. 